This is the pre-peer reviewed version of the following article: Singh, S. P.,

Joneson, E., Singh, J. and Grewal, G. (2008), Dynamic analysis of

less-than-truckload shipments and test method to simulate this environment.

Packaging Technology and Science, 21: 453-466. doi: 10.1002/pts.787, which has

been published in final form at http://onlinelibrary.wiley.com/doi/10.1002/pts.787/abstract

\title{
Dynamic Analysis of Less-than-truckload Shipments and Test Method to Simulate This Environment
}

S. P. Singh

Michigan State University, East Lansing, MI, USA

E. Joneson

Lansmont Technical Services Group, Lansmont Corporation, Lansing, MI, USA

\section{J. Singh}

Cal Poly State University, San Luis Obispo, CA, USA

G. Grewal

International Packaging Consultancy Inc., East Lansing, MI, USA

\section{ABTRACTS}

This paper provides results from a comprehensive data measurement study that analyzed the vibration dynamics produced inside the trailers used for less-than truckload (LTL) shipments. The trailers used for this segment of the package transportation environment are very different in size and suspension than those used for full truckload shipments. This study measured the vertical, lateral and longitudinal vibration inside a trailer as a function of road surface. In addition, the study developed a video showing freight movement inside the trailer to determine physical displacement and shifting of the loads. A set of recommendations was developed to safely load and transport LTL shipments to reduce damage claims.

KEYWORDS: less-than-truckload; dynamic; analysis; simulation 


\section{INTRODUCTION}

Single shipments consisting of large boxes, crates, tires, drums, coils and pallets are shipped using lessthan-truckload carriers. The freight gets loaded and unloaded inside trailers with a mix of other products going to different destinations and customers. Different combinations of stacked loads are created. As a result of all these variables, this segment of the truck transport industry is challenged with some of the highest amounts of damage worth hundreds of millions of dollars annually in the USA. A majority of these claims are less than $\$ 200$. This study was performed to assist carriers understand the dynamic conditions inside these trailers, and quantify and visually correlate to actual freight movement and damage. ${ }^{1}$

There has been very limited information on the dynamics inside trailers that are used for LTL shipments. Carriers use special trailers for this segment of the business that are shorter than full truckload shipments, but can be hitched together to build two or three trailer-long highway trains. Also, there is a mix of load with varying density throughout each trailer, making the ride different than full truckload shipments. $^{2}$

This study involved measuring and analyzing the dynamics that occur inside the trailer as a function of road surface irregularities, and vehicle size and speed. The test shipments were carried out on a highway, inner-city roads, unpaved roads and parking areas. Various combinations of loads were used inside the trailer to determine safe loading, blocking and bracing requirements. The loads consisted of a range of packaged products that consisted of glass containers, palletized boxes, plastic liquid drums, large panel doors and tires. Also, a video camera was used to study the effect of the vibration input on load stability.

There has been very limited information on vibration levels inside trailers used for LTL shipments. Marcondes et al. ${ }^{3}$ studied the effects of vibration input to trailers as a function of package types used in 
LTL shipments. The study used six vibration simulators, each supporting the vehicle and trailer tires. The palletized loads measured $1000 \times 1200 \times 1500 \mathrm{~mm}$ and weighed between 500 and $1000 \mathrm{~kg}$. All palletized boxes were stretch wrapped on wooden pallets. There were some key results from this study that are summarized as follows:

- Based on response accelerations recorded in packages as a result of input vibration to the truck, the rear of the truck trailer was not always the worst position for acceleration magnification in LTL shipments.

- Frequency response functions were used to determine the contributions of front axle, fifth wheel and rear axle to the overall rear truck bed acceleration. It could not be generalized from this study that one position was better than another inside the trailer.

- Magnification factors from the truck bed to the packages between 0.4 and 6.0 were present at both front and back.

- The front axle and the fifth wheel also contributed to the input to the rear truck bed. The front axle contributed about $20 \%$ of the vibration input to the rear truck bed. Similarly, the fifth wheel contributed about $30 \%$. The $50 \%$ remainder was due to the input from the rear axle.

A second study performed by Pierce and Young ${ }^{4}$ measured the impact levels and drop heights to instrumented packages that were shipped in two different LTL carries to two different destinations (Texas and California) from Rochester, New York. This study presented data for drop heights based on frequency of occurrence, and showed that these levels could be different than those experienced by single-parcel shipments by carriers such as Federal Express (FedEx) and United Parcel Service (UPS). This study did not collect any data for vehicle dynamics. No results were presented for vibration levels inside the trailers. 
Singh and Marcondes ${ }^{5}$ showed a comparison of vibration levels in truck shipments as a function of payload and suspension type. Air-ride suspensions showed a better performance and lower vibration levels than leaf spring trailers. Also, the smaller-sized trailers produced higher vibration levels.

Focusing on LTL trucks, which are the main carriers for single shipments, the origin of all dynamic shock and vibration levels come from two sources:

1. External sources such as road or surface irregularities, braking and forward acceleration, and driver control.

2. Internal sources due to the vehicle itself such as engine vibration, drive mechanisms and wheel unbalance. ${ }^{6}$

The purpose of this study was to understand the vibration dynamics of loaded truck LTL shipments. The objectives were as follows:

1. Measure and analyze the vertical, lateral and longitudinal vibration levels in LTL trailers as a function of road surface conditions.

2. Recommend methodology to simulate these conditions in lab-based tests.

\section{INSTRUMENTATION AND RECORDING PARAMETERS}

This study used electronic data recorders with built-in triaxial accelerometers to measure the vibration levels for vertical, lateral and longitudinal movements. The recorders were made and provided by Lansmont Corporation (Monterey, CA, USA) for this study, and were mounted on the trailer base structure. Figure 1 shows the installation of the instrument directly to the trailer floor over the rear axle. The instruments were attached to an aluminum mounting plate using four hexhead bolts, and were then rigidly attached directly to the trailer floor with four wood screws. Although the instruments were 
mounted over both the nose and rear suspension of each measured trailer, only the data from the rear of the measured trailers is presented since the analysis indicated it was comparably more severe.

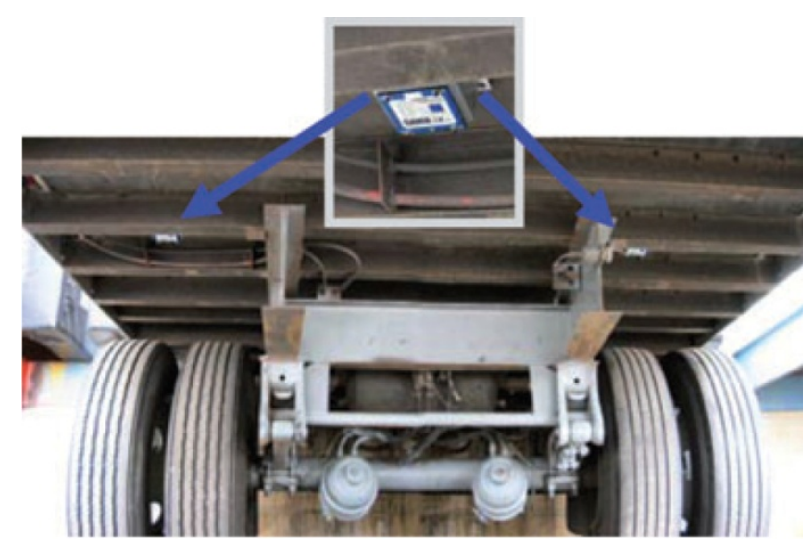

Figure 1. Recorder mounted on the trailer base.

The equipment used for data collection was Lansmont SAVER 3X90 (Lansmont Corporation). The recording parameters were as follows:

- Timer-triggered event interval: every $15 \mathrm{~s}$

- Timer event size: $2 \mathrm{~s}$

- Signal-triggered event threshold level: $1 \mathrm{G}$

- Signal event size: $2 \mathrm{~s}$

- Pre-trigger data: $20 \%$

- Post-trigger: $80 \%$

Timer-triggered event samples were taken every $15 \mathrm{~s}$ in addition to samples that exceeded the trigger level of $1 \mathrm{G}$. Most vibration runs for data collection were an hour long. In a typical run, approximately 500 events were measured and analyzed to create power density spectrums, which represented approximately two-thirds that was trigger-generated, and one-third that was due to the timed data capture every $15 \mathrm{~s}$. 


\section{RESULTS AND DISCUSSION}

Over the last 5 years, the International Safe Transit Association (ISTA), whose predominant goal is to develop test methods for pre-shipment testing to reduce transport damage, has worked on developing new test methods for various types of transport and handling conditions. ${ }^{7}$ The association has a membership that consists of shippers, transportation carriers, test laboratories and academia. ISTA is investigating the development a new test method (currently being designated as a future Project 3B) for simulating the conditions loads are exposed to in LTL transport. The results of the measured vibration levels were analyzed and reported in the form of power spectral density (PSD) spectra. The PSD plots represent the vibration intensity measured on the truck bed as a function of road conditions. Each of the plots includes a representation of ISTA's Steel Spring truck vibration profile (reference procedures 3H and $4 A B$ ), displayed at its 'field level' root mean square acceleration (Grms) intensity for comparison purposes. ${ }^{7}$ Figures $2-4$ represent paved roads and distribution routes including highway and city streets.

Figures 5-7 represent vibration levels in the terminal and parking areas. These regions where trailers often travel at low speeds can result in severe lateral vibration movement due to unpaved conditions and presence of potholes. Figures 8-10 represent data measured from a 'pup' trailer that was pulled behind the fifth wheel trailer. These vibration levels are different than those measured in the fifth wheel trailers and should be accounted for in simulation methods. Table 1 summarizes the vibration levels for the PSD plots in Figures 2-10. Summary Average PSD plots were created by performing composite analysis on timer-triggered events possessing a Grms level of 0.04 or greater (minimum threshold that clearly indicates vehicle motion). To highlight higher severity level vibration inputs, summary PSD plots were also created representing each of the three day's vertical and lateral inputs. The additional two analysis criteria used were

1. timer-triggered top 20th percentile Grms events, and 
2. all events (timer and signal) possessing a peak acceleration level of $1 \mathrm{G}$ or greater.

Table 2 shows the Grms for the summary averages for all axes. Figures 11 and 12 show the setup required to instrument and power the video equipment for recording the actual freight shifting and movement during the measurement study. Results of the video were used to develop training methods to better secure loads and prevent shifting by using techniques such as interlocking, shelf loading and cornerstone loading. These methods allowed to stair-step the freight from high in the nose to low in the back of the trailer. In addition, smaller and lighter products and packages were placed on top of the larger, heavier units. Also, using interlocking (placing packages among each other), lateral and longitudinal load securement could be achieved. These multiple factors play a role in insuring a safe and damage-free delivery of goods in this challenging single-shipment transportation environment. 


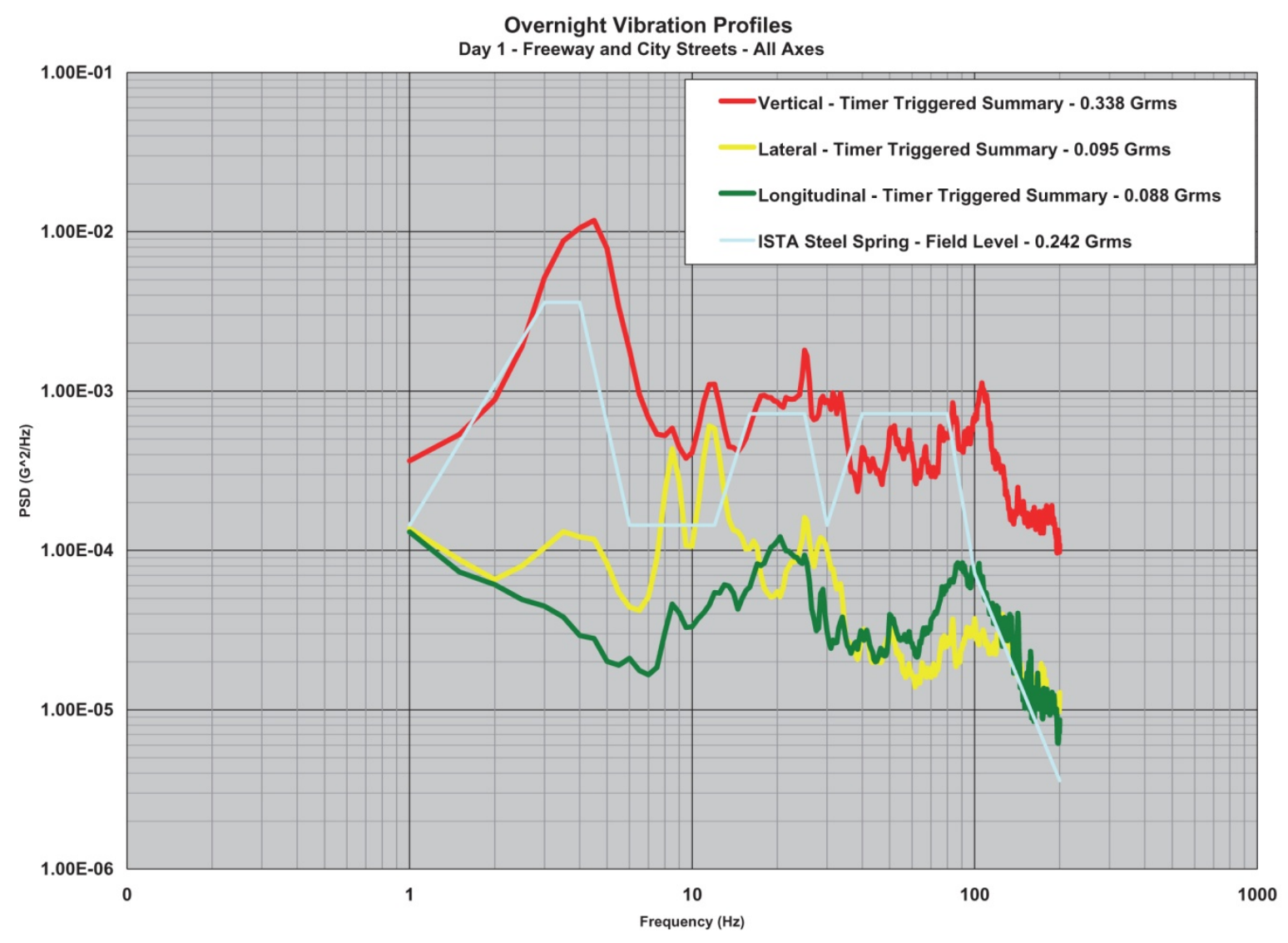

Figure 2. Power density spectrums of vertical vibration levels in city streets and highway in LTL trailer.

Summary averages, all axes. 


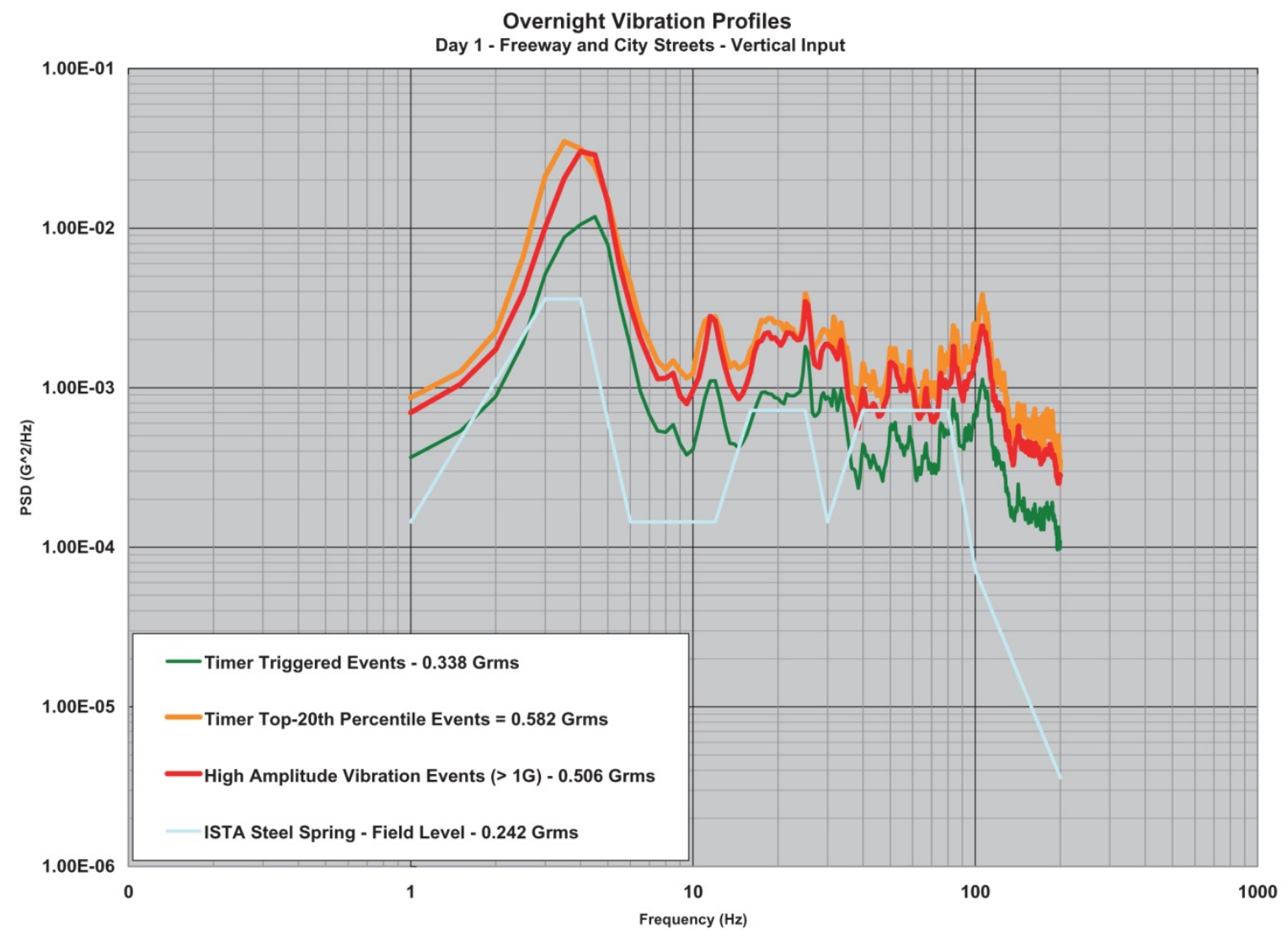

Figure 3. Power density spectrums of vertical vibration levels in city streets and highway in LTL trailer. Vertical input. 


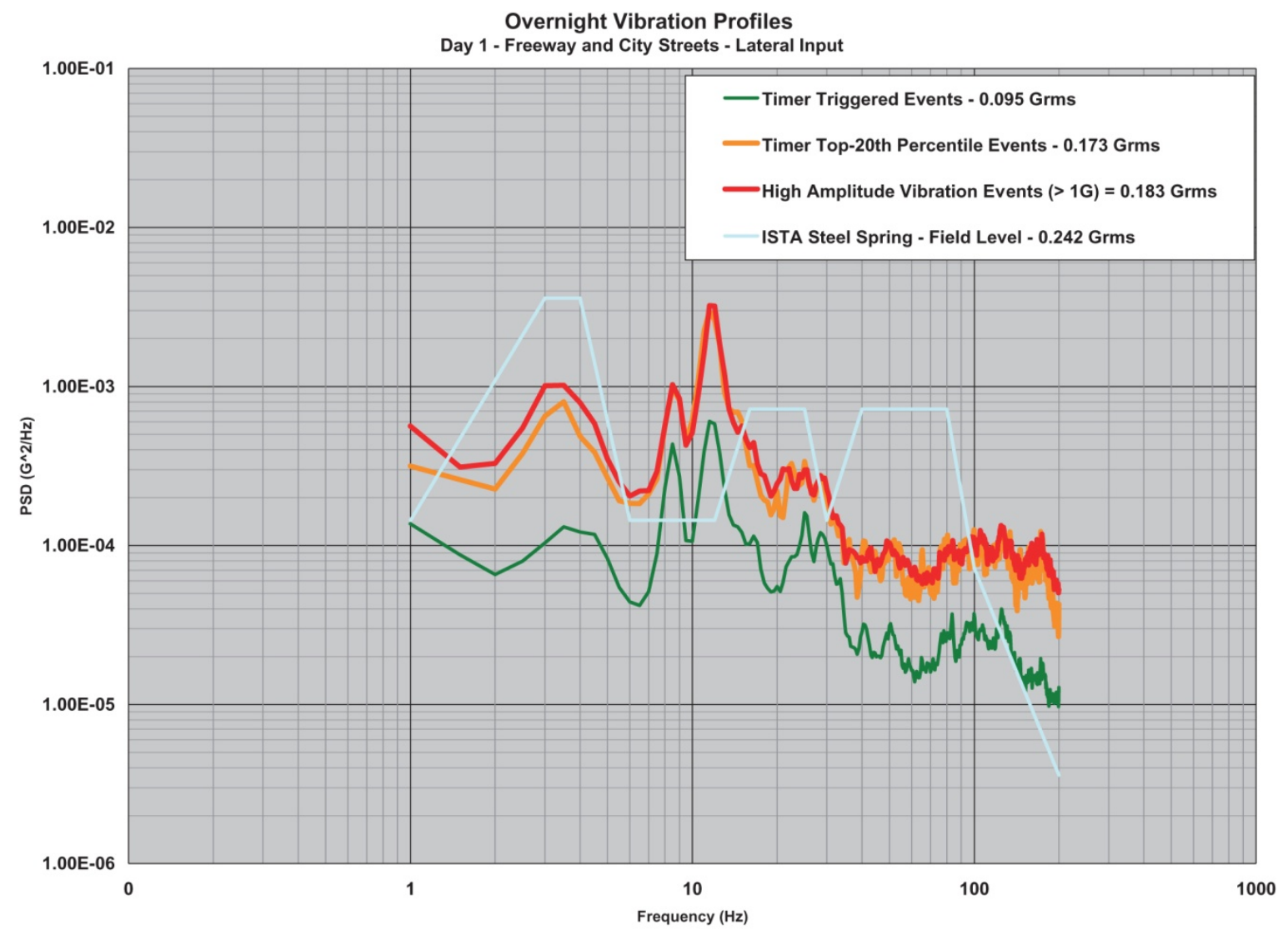

Figure 4. Power density spectrums of vertical vibration levels in city streets and highway in LTL trailer.

\section{Lateral input.}




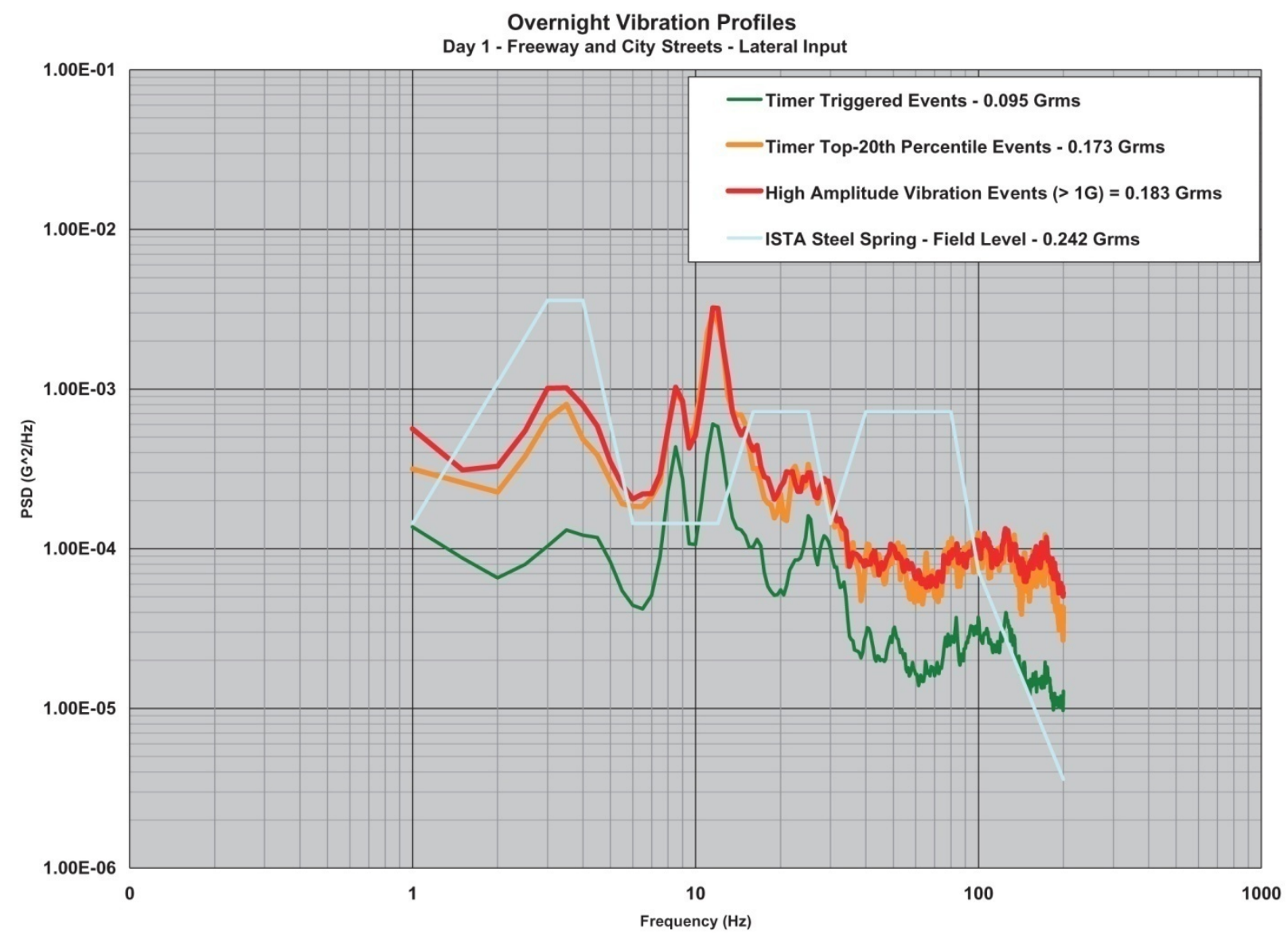

Figure 5. Power density spectrums of vertical vibration levels in parking areas, terminal and unpaved roads in LTL trailer. Summary averages, all axes. 


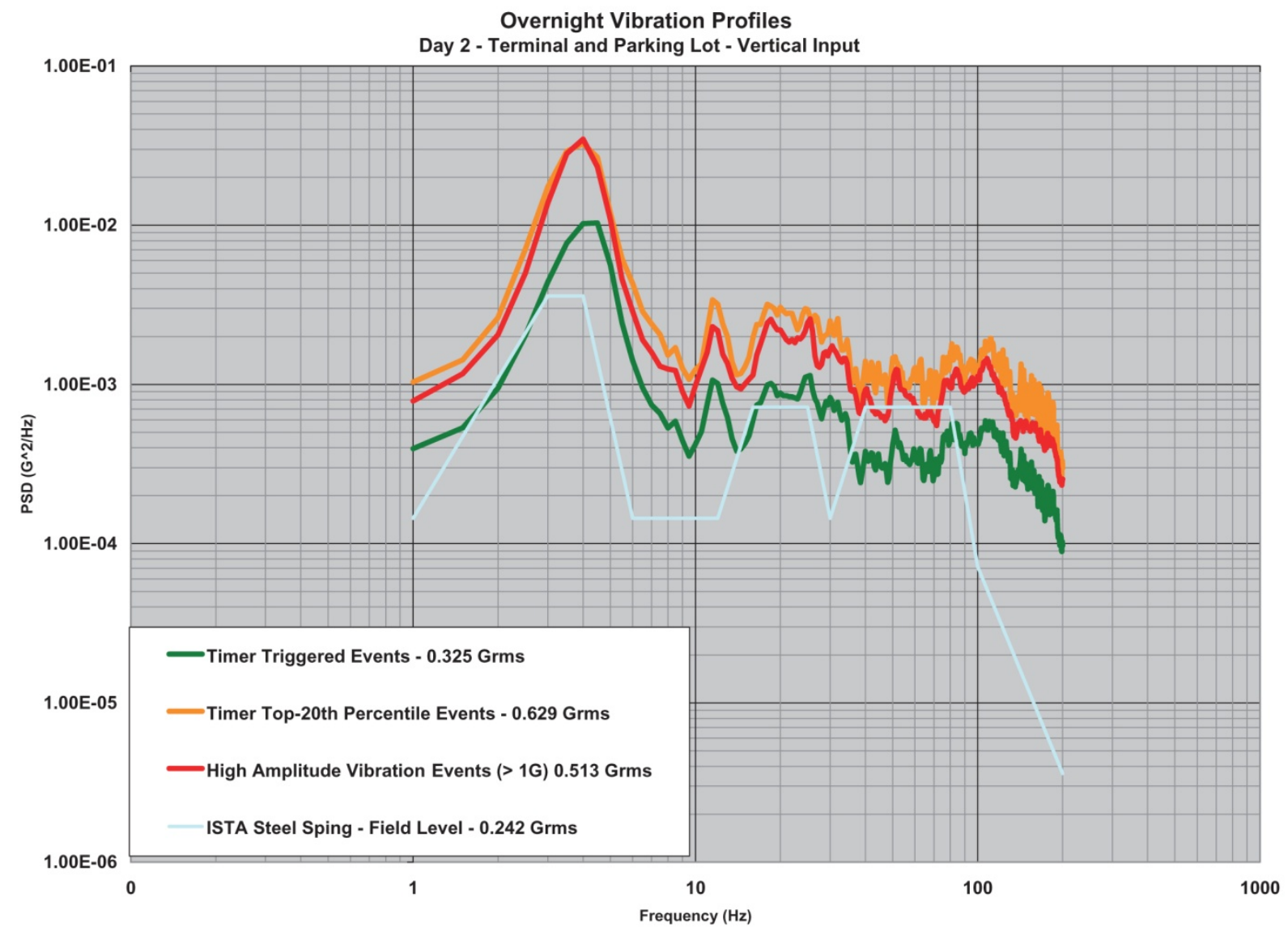

Figure 6. Power density spectrums of vertical vibration levels in parking areas, terminal and unpaved roads in LTL trailer. Vertical input. 


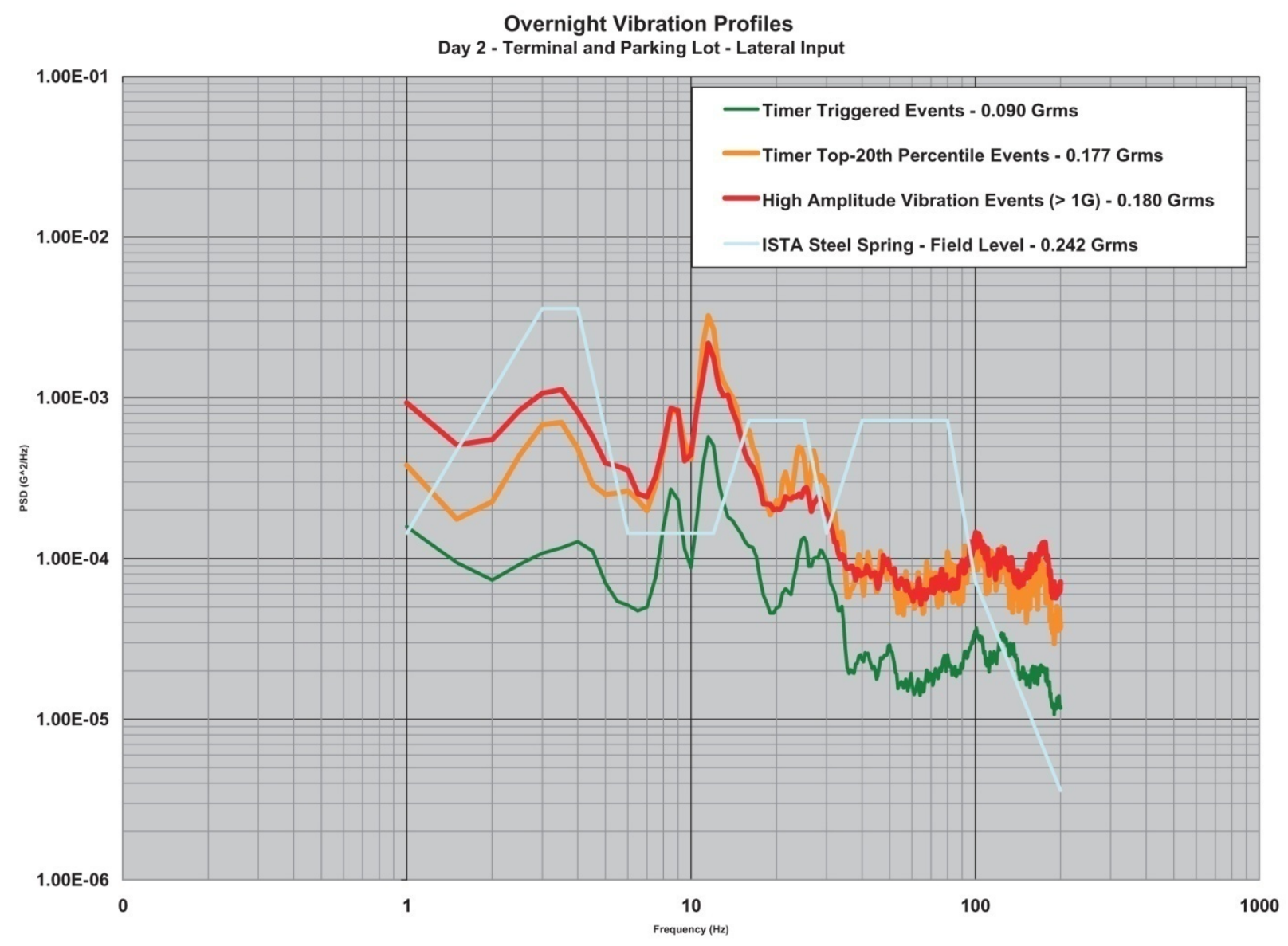

Figure 7. Power density spectrums of vertical vibration levels in parking areas, terminal and unpaved roads in LTL trailer. Lateral input. 


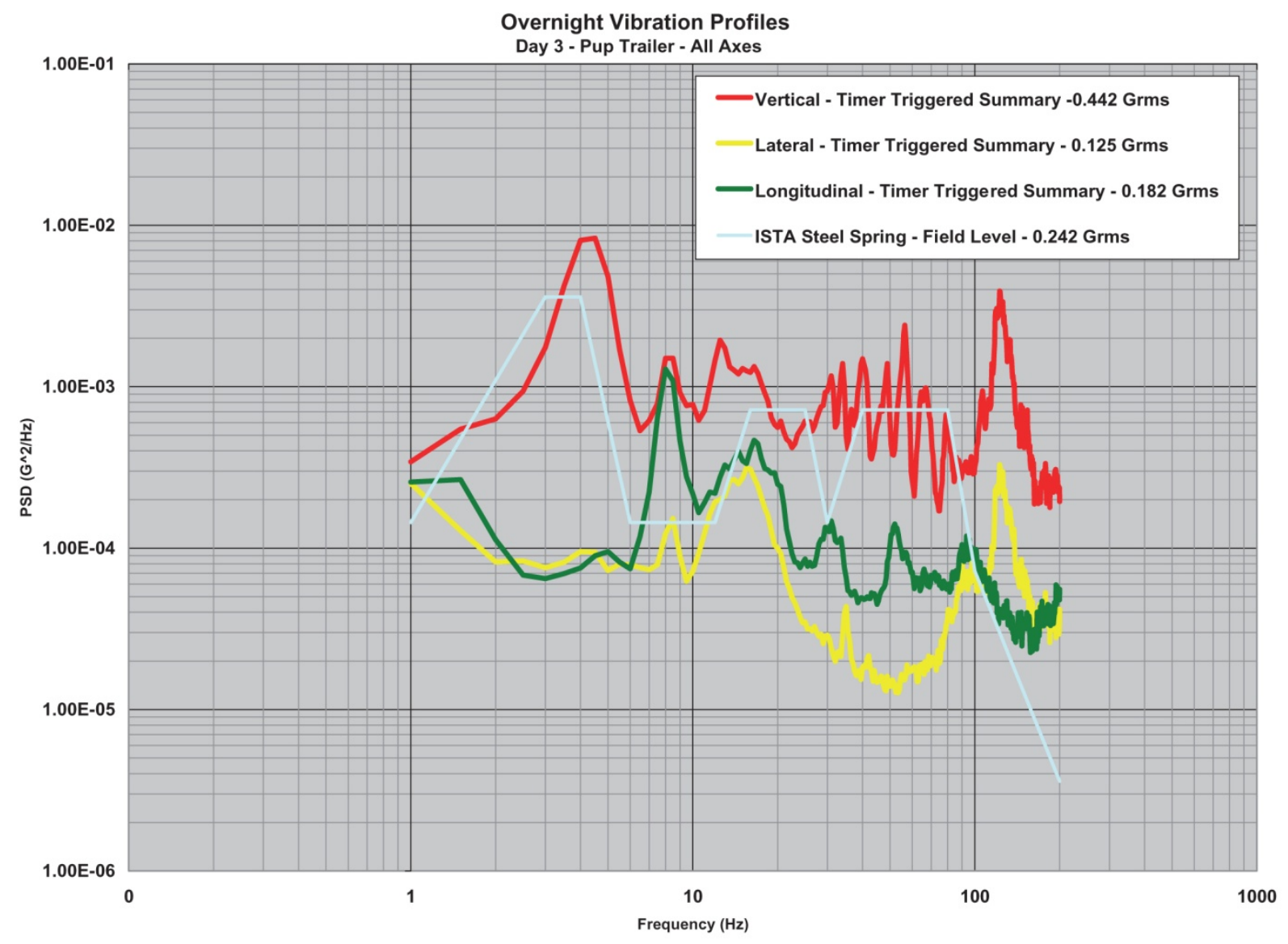

Figure 8. Power density spectrums of vertical vibration levels in city streets and highway in pup trailer.

Summary averages, all axes. 


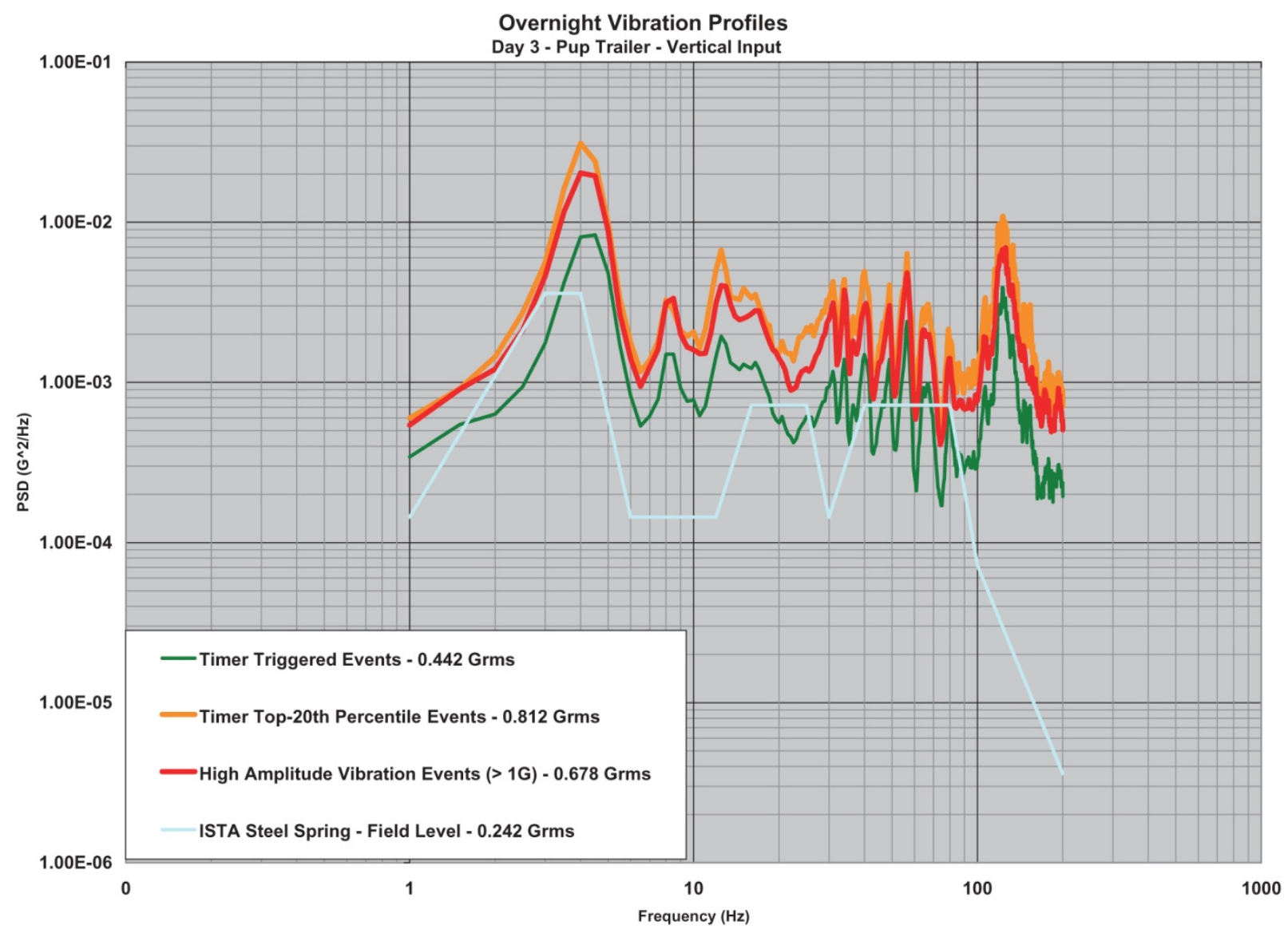

Figure 9. Power density spectrums of vertical vibration levels in city streets and highway in pup trailer. Vertical input. 


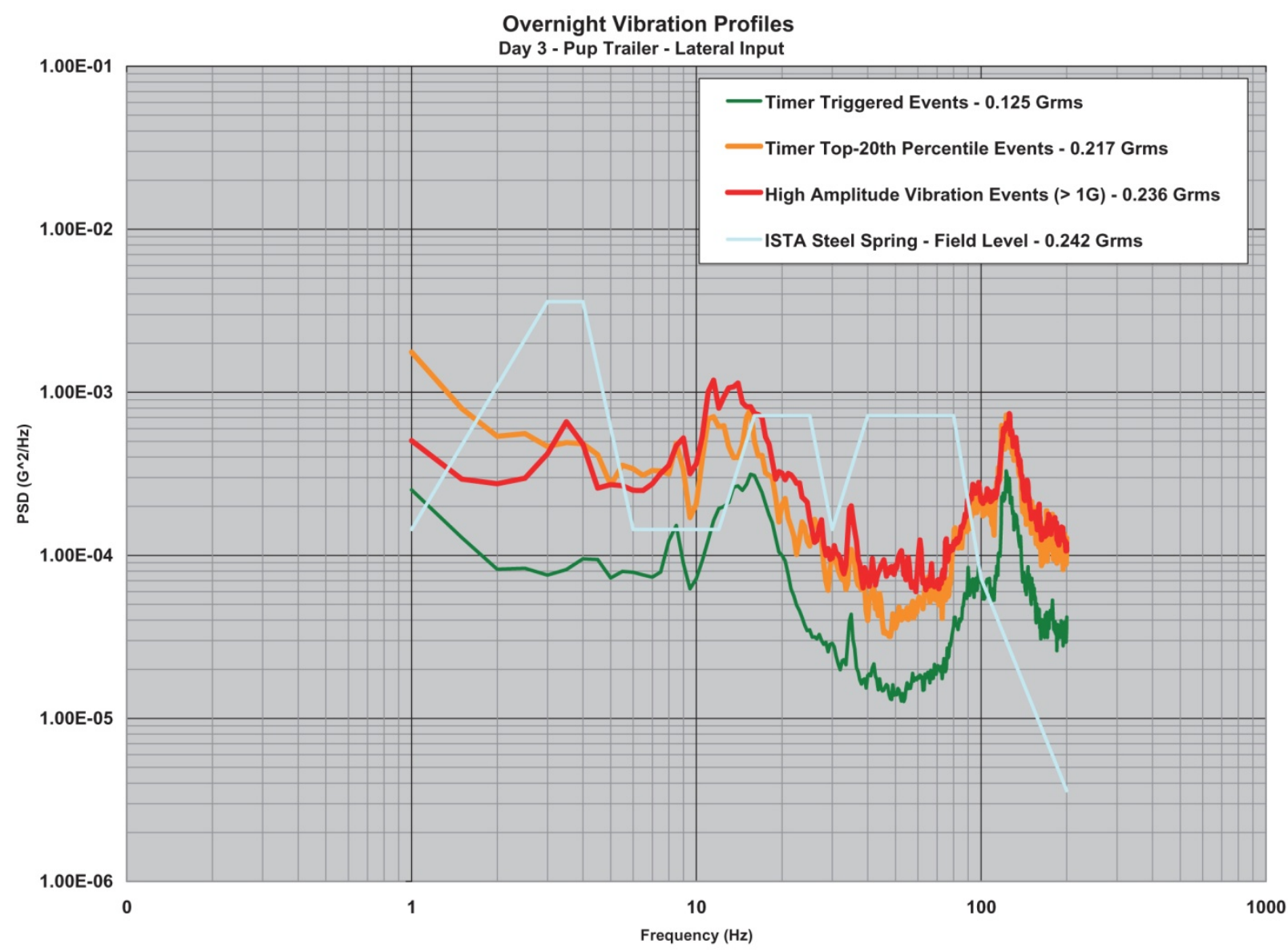

Figure 10. Power density spectrums of vertical vibration levels in city streets and highway in pup trailer.

Lateral input.

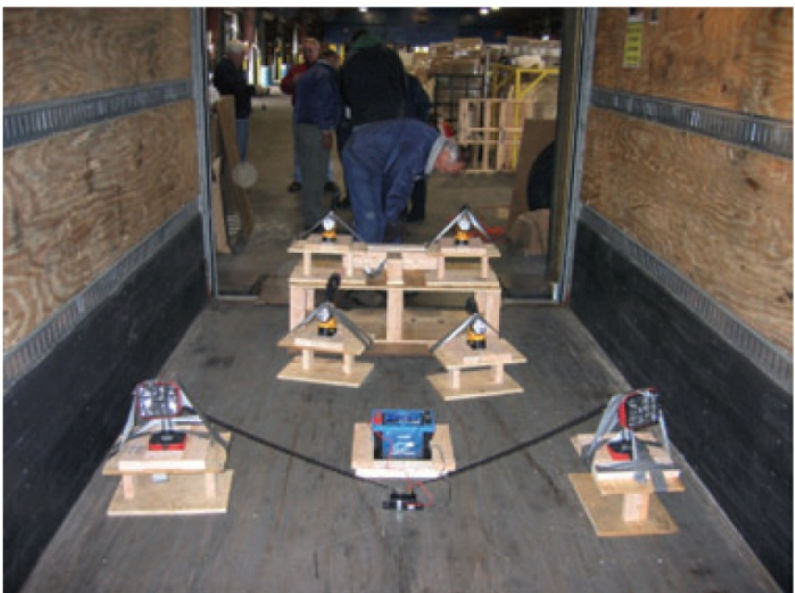

Figure 11. Video and light equipment setup for recording live freight movement. 


\begin{tabular}{|c|c|c|c|c|c|c|}
\hline \multirow[b]{3}{*}{$\begin{array}{l}\text { Source of } \\
\text { vertical } \\
\text { vibration } \\
\text { levels }\end{array}$} & \multicolumn{6}{|c|}{ Grms } \\
\hline & \multicolumn{3}{|c|}{ Vertical input } & \multicolumn{3}{|c|}{ Lateral input } \\
\hline & $\begin{array}{l}\text { Timer- } \\
\text { triggered } \\
\text { events }\end{array}$ & $\begin{array}{l}\text { Timer top } \\
\text { 20th } \\
\text { percentile } \\
\text { events }\end{array}$ & $\begin{array}{l}\text { High- } \\
\text { amplitude } \\
(>I G) \\
\text { vibration } \\
\text { events }\end{array}$ & $\begin{array}{l}\text { Timer- } \\
\text { triggered } \\
\text { events }\end{array}$ & $\begin{array}{l}\text { Timer top } \\
20 \text { th } \\
\text { percentile } \\
\text { events }\end{array}$ & $\begin{array}{l}\text { High- } \\
\text { amplitude } \\
(>\mid \mathrm{G}) \\
\text { vibration } \\
\text { events }\end{array}$ \\
\hline $\begin{array}{l}\text { City streets } \\
\text { and highway } \\
\text { in LTL trailer }\end{array}$ & 0.338 & 0.582 & 0.506 & 0.095 & 0.173 & 0.183 \\
\hline $\begin{array}{l}\text { Parking } \\
\text { areas, } \\
\text { terminal and } \\
\text { unpaved } \\
\text { roads in LTL } \\
\text { trailer }\end{array}$ & 0.325 & 0.629 & 0.513 & 0.090 & 0.177 & 0.180 \\
\hline $\begin{array}{l}\text { City streets } \\
\text { and highway } \\
\text { in pup trailer }\end{array}$ & 0.442 & 0.812 & 0.678 & 0.125 & 0.217 & 0.236 \\
\hline
\end{tabular}

Table 2. Grms values for the summary averages for all axes

\begin{tabular}{llcc} 
& & \multicolumn{2}{c}{ Grms } \\
Source of vertical vibration levels & & Summary averages, all axes \\
\cline { 2 - 4 } & Vertical & Lateral & Longitudinal \\
\hline City streets and highway in LTL trailer & 0.338 & 0.095 & 0.088 \\
Parking areas, terminal and unpaved roads in LTL trailer & 0.325 & 0.090 & 0.091 \\
City streets and highway in pup trailer & 0.442 & 0.125 & 0.182 \\
\hline
\end{tabular}




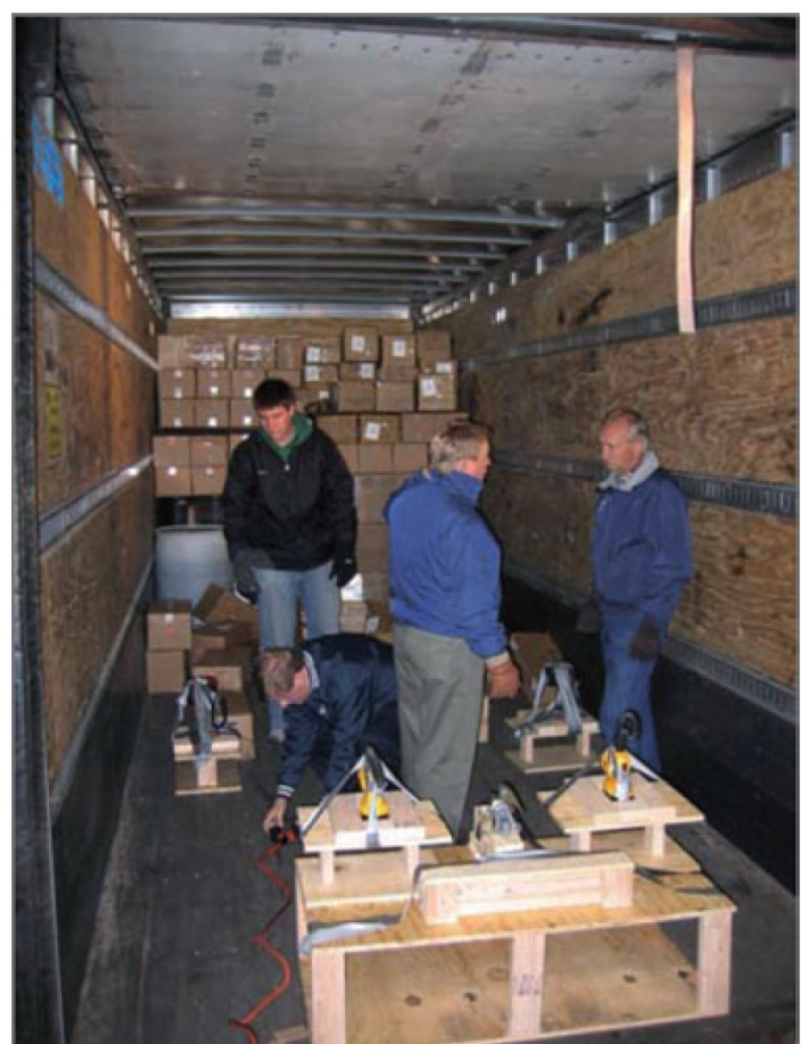

Figure 12. Recording equipment setup at rear of trailer.

\section{CONCLUSIONS}

The study concludes the following:

- Comparison of the LTL data to ISTASteel Spring data shows that the measured vertical vibration levels are more severe than implied 'standard' levels used for existing test methods. ISTA is currently evaluating the use of the data from this study for its Procedure 3B test method to simulate vibration in LTL shipments.

- Video footage of load shifting inside the trailer showed that the LTL environment requires blocking and bracing, and the absence of load restraining methods can result in excessive shifting and damage. 
- The measured levels in lateral should be used in conjunction with vertical levels for packages and products that may not be perfectly cubed in the trailer and result in void spaces.

- The higher vertical and lateral inputs are of more significance in the LTL environment as compared to the full truckload vibration levels as previously measured, ${ }^{8}$ due to the nature of dissimilar products being shipped through this mode of transport. Different sizes, shapes, weights, etc. increase the risk from these types of high intensity and off-vertical axis input. More void space means the likelihood of more movement and load shifting as a response to the inputs.

- There is a difference between vibration levels measured in 'pup' trailers than in fifth wheel trailers.

\section{ACKNOWLEDGEMENTS}

The authors would like to acknowledge the Center for Distribution Packaging Research at Michigan Stat University and the ISTA for funding and assisting with the study.

\section{REFERENCES}

1. Avery J. Video on Freight Damage and Losses in Less than Truck Load Shipments. Overnite Transport Inc.: Greensboro, NC, 2005.

2. Singh SP, Joneson E. Video and measurement of dynamics of a less than truck load shipment. Proceedings of Dimensions 06. International Safe Transit Association: San Antonio, TX, 2006.

3. Marcondes J, Singh P, Burgess G. Dynamic analysis of a less than truck load shipment. Paper \#88WA/EEP-17, ASME. 
4. Pierce S, Young DE. Package handling in less-than truckload shipments: focused simulation measurement and test development. Proceedings of ISTA CON 98. International Safe Transit Association: East Lansing, MI, 1998.

5. Singh SP, Marcondes J. Vibration levels in commercial truck shipments as a function of suspension and payload. J. Testing and Evaluation ASTM 1992; 20(6): 466-469.

6. Harris C, Piersol A. Harris Shock and Vibration Handbook, ISBN 0070269203, McGraw-Hill Professional Publishing, Dubuque, IA 52002, USA.

7. http://www.ista.org [accessed 10 August, 2006].

8. Singh J, Singh P, Joneson E. Measurement and Analysis of U.S. Truck Vibration for Leaf Spring and Air Ride Suspensions and Development of Tests to Simulate these Conditions. Packaging Technology and Science, 2006; 19(6): 309-323. 